\title{
TRATAMIENTO JURIDICO DE LA COMPETECIA DEL JUEZ, EN LOS PROCESOS DE VIOLENCIA FAMILIAR CON SU PARALELO FALTA $O$ DELITO CONTRA LA PERSONA
}

\author{
JUAN CARLOS MENDIZÁBAL GALLEGOS *
}

\section{RESUMEN}

El objeto del presente trabajo, consiste en efectuar una recorrida explicación de la inconveniencia de una doble vía en temas de violencia familiar, faltas 0 delitos perpetrados por un miembro de familia en su entorno familiar. El plan general consistirá en explicar, las razones para determinar la competencia exclusiva del Juez de familia, apoyándose básicamente en dos conceptos muy concretos: uno primero, el Derecho de Familia como institución sui géneris del Derecho, merece un tratamiento legislativo diferenciado, «trascendente para unificar la competencia de Juez de Familia en casos de violencia familiar así como delitos o faltas». Uno segundo, el tratamiento legal sobre la triple competencia regulada en la ley 26260 «Ley de Protección frente a la Violencia Familian y su modificatoria Ley $N^{\circ} 26763$ no es el camino correcto para disminuir la «carga procesal» en el caso peruano, menos incide en la necesidad de diferenciar la regulación de las relaciones jurídico genéricas de las relaciones jurídico familiares.

El ámbito dentro del que se desarrolla la investigación es el de la dogmática jurídica. A un cuando puedan resultar muy ilustrativas las investigaciones sociológicas e históricas del problema planteado nos circunscribimos al ámbito señalado.

PALABRAS CLAVE: Familia, violencia familiar, competencia, cargaprocesal.

\section{ABSTRACT}

The object of the present investigation, consists of carrying out one crossed explanation of the inconvenience of one double via in subjects of familiar violence, lack or crimes perpetrated by a member of family in its familiar surroundings.

The general plan will consist of explaining, the necessity to basically determine the exclusive competence of the Judge of Family, leaning in two very concrete concepts: First, the Right of Family like institution sui géneris of the Right, deserves a legislative treatment differentiated, «important to unify the competence of Judge of Family in cases of familiar violence as well as crimes or lack». Second, the legal treatment on the triple competence regulated in Law 26260 "Law of Protection as opposed to the Familiar Violence» and its modifying Law $N^{\circ} 26763$ is not the correct way to diminish the "condition of parties to an action» in the Peruvian case, less affects the necessity to differentiate the regulation from the generic relations legal of the familiar relations legal. The scope within which the research is carried out is the dogmatic legal. To when can be very illustrative historical and sociological investigations of the problem we limit to the designated area.

KEYWORDS: Family, Family Violence, competence, procedural burden.

\footnotetext{
* Docente ordinario de la Escuela Profesional de Derecho de la Universidad Nacional del Altiplano
} 


\section{INTRODUCCIÓN}

Los conceptos de violencia física, psicológica, coacción, violencia sexual y maltrato sin lesión, está íntimamente vinculada al supra concepto «violencia familiar», de tal suerte que en muchos de los casos, las denuncias formuladas ante el Ministerio Público - Policía Nacional, dan lugar a dos procesos judiciales: uno, ante Juez de Familia, y paralelamente el segundo, al Juez Penal o Juez de Paz letrado, este último, dependiendo si el hecho constituye delito o falta. Así se tiene del Artículo $8^{\circ}$ del Decreto Supremo $N^{\circ}$ 006-97-JUS Texto Único Ordenado de la Ley $N^{\circ} 26260$, Ley de Protección frente a la Violencia Familiar. «El atestado policial será remitido al Juez de Paz o Fiscal Provincial en lo Penal, según corresponda, y al Fiscal de Familia, para ejercer las atribuciones que le señala la presente ley».

Observo en ello, con frecuencia, un problema en los tribunales, referido a la doble competencia del Juez. Al inconveniente se le ha consignado con la siguiente interrogante: ¿En qué medida la competencia del Juez, incrementa la carga procesal en los juzgados de Familia, Juzgados Penales o Juzgados de Paz Letrado, cuando se invoca proceso de violencia familiar ante Juez de Familia con su paralelo faltas o delitos derivado de los mismos hechos?.

Para introducirnos en el tema, el presente trabajo cuenta con dos propósitos muy concretos: El primero, referido a las disposiciones de la "competencia del aparato jurisdiccional» para proteger a la Familia de la Violencia Familiar. La descripción de esta institución jurídica, como actos judiciales determinados en nuestra legislación, viene hacer nuestro objeto de estudio, por ello, procurare fijar los principios cardinales del enjuiciamiento de la Violencia Familiar, Ley № 26260; el segundo, el de demostrar al lector, la constatación de discrepancia entre validez y vigencia de la norma jurídica que regula la institución jurídica de la violencia familiar (esto es, entre el derecho que es y el derecho que jurílicamente debe ser). La inconveniencia narrada, supone, gastos innecesarios de los recursos logísticos del Estado. Resultará también valido, cuestionarse sobre el atentado de los principios «no bis in ídem» y «economía procesal», el que tendrá en cambio, un desarrollo modesto por razones de interés en un articulo independiente.
Por las consideraciones expuestas, los objetivos de la presente investigación se reducen:

\subsection{Objetivos generales:}

Clasificar la carga procesal de los tribunales civiles y penales derivados de procesos de Violencia Familiar.

\subsection{Objetivos específicos}

Determinar la competencia exclusiva, derivada de violencia familiar por parte de los tribunales penales y civiles, por cuanto ofrecen remedios similares.

En este sentido, pensamos que el derecho no debe de ser entendido como un ente inmóvil sin movimiento, este trabajo debe ser entendido como un intento de descongelar la vida de la ley. Además requiere que sea tomada y de ninguna manera pueda considerarse como un producto final.

\section{MATERIALES Y METODOS DE INVESTIGACION}

Como refiere Emilio Betti (Betti, 1969, pág. 1) «Respecto a la posición metodológica que el jurista debe adoptar cuando se propone el estudio de instituciones y relaciones previstas en el ordenamiento jurídico (...) la investigación científica debe puntualizarse sobre el problema practico que el derecho positivo, (...) ha resuelto mediante la adopción de normas que representan la solución de un conflicto de intereses considerados contrapuestos y comparativamente valorados en su entidad social».

Por ello, el método de investigación a seguir, en el presente trabajo, es el de la dogmática jurídica, de allí que Luigi Ferrojoli (Ferrajoli, 1989) explica el objeto y función de la teoría del derecho, esto es, a que se refiere y para qué sirve esta particular disciplina jurídica. A su juicio, la teoría del derecho se refiere a las normas jurídicas y a ciertos hechos vinculados con ellas, desde los que consisten en la creación o aplicación de dichas normas hasta los que determinan su eficacia o ineficacia. "uno de los objetivos principales de la teoría del derecho es constatar tres divergencias deónticas que afectan a tres discursos distintos sobre el derecho. La primera es la que se da entre justicia y validez, de interés para la filosofía política; la segunda se da entre 
validez y vigencia, de interés para la dogmática jurídica; y la tercera se da entre vigencia y eficacia, de interés para la sociología del derecho».

En ese sentido, la validez y vigencia de la norma jurídica, se pone en evidencia, al realizar el presente estudio descriptivo. El fenómeno específico se detalla, la inconveniencia de seguir dos procesos por los mismos hechos (violencia Familiar y su paralelo faltas o delito). De nada serviría la doble carga procesal, si se atenta el "principio de economía procesal» el «no bis in ídem», si el modo de proceder para alcanzar la justicia, se encuentra bifurcada innecesariamente (penal o civil), cuando el fin del caso que se presenta "familia», debe estar sujeto a determinados principios de la especialidad, afín de evitar que la justicia sea sacrificada a la imprevisión del que la pide, o al error, parcialidad o mala dirección del que debe otorgarla.

En cuanto a la población a estudiar, ello recae en el número de expedientes judiciales por «violencia familiar» instaurados en el primero y segundo Juzgado de Familia de la Provincia de Puno durante el año 2013, así como, los expedientes judiciales derivados por los mismos hechos (faltas contra la persona) del primero, segundo, tercero y cuarto Juzgado de Paz Letrado de la Provincia de Puno durante el año 2013.

El número de expedientes judiciales por violencia familiar se detallan en el cuadro 01 y 02 :

\begin{tabular}{|c|c|c|c|}
\hline $\begin{array}{l}\text { NÚMERO DE } \\
\text { EXPEDIENTES }\end{array}$ & MATERIA & $\begin{array}{l}\text { PRNER JUZGADO } \\
\text { DE FAVILIA }\end{array}$ & ANO \\
\hline 1232 & $\begin{array}{c}\text { Demanda de: } \\
\text { Violencia Familiar }\end{array}$ & 1JFP & 2013 \\
\hline \multicolumn{4}{|l|}{ Cuadro $\mathrm{N}^{\mathrm{N}} 02$} \\
\hline $\begin{array}{l}\text { NÚMERO DE } \\
\text { EXPEDIENTES }\end{array}$ & MATERIA & $\begin{array}{c}\text { SEGUNDO JUZGADO } \\
\text { DE FAMILIA }\end{array}$ & AÑO \\
\hline 1238 & $\begin{array}{c}\text { Demanda de: } \\
\text { Violencia Familiar }\end{array}$ & 2 FP & 2013 \\
\hline
\end{tabular}

Conocidas las poblaciones de estudio, se diseñaron los instrumentos de comparación de información, para determinar el número de procesos derivados de los Juzgados de Familia a los Juzgados de Paz Letrado.

\section{DISCUSIÓN TEÓRICA}

Como quiera que, lo que nos interesa en el presente trabajo es la unidad del Derecho procesal en faltas o delitos y su paralelo violencia familiar derivado de los mismos hechos familiares, nos proponemos llegar a este objetivo, con el análisis de la jurisdicción y la Teoría General del Proceso, es a través de estas, cómo podremos delimitar la naturaleza jurídica del Derecho de familia.

El otro objetivo trazado en la presenté investigación, esto es, relativo a la competencia del Juez de familia, tendrá en el presente trabajo, a medir la inversión negativa de los recursos logísticos del Estado en lo regulado por la Ley de Violencia Familiar, Ley $\mathrm{N}^{\circ}$ 26260 y su modificatorias.

\subsection{Jurisdicción y proceso}

Si reconocemos a la Jurisdicción, como función estatal que tiene el cometido de dirimir conflictos entre los individuos para imponer el derecho y que su etimología iuris dictio, significa decir derecho, no solo para juzgar sino también ejecutar lo juzgado, esta será necesariamente su función. El Poder Judicial existe, en cuanto existe el hombre como ser social conflictivo, y que la ley concibe a la heterocomposición, una verdadera y propia forma moderna en la cual el Estado se apropia de la facultad sancionadora llamada jurisdicción.

Como indica Juan Montero Aroca; (Montero Aroca, 1979, pág. 28) «la jurisdicción (...) es necesariamente única, es imposible conceptualmente que un Estado tenga más de una jurisdicción. Sin embargo, tradicionalmente se ha venido hablando de jurisdicción civil, penal etc. (...) No existen, pues, varias jurisdicciones sino varias manifestaciones de una única jurisdicción».

La importancia práctica de la jurisdicción, supone delimitar el concepto de proceso, en efecto, el proceso es el instrumento de la jurisdicción, para realizar un debate ordenado, mediante cuyo uso se llega a la demostración de una realidad propuesta, en cumplimiento fiel a normas pres establecidos. Veremos a continuación, como un tema de violencia familiar y su paralelo penal, requiere unidad procesal o por lo menos un tratamiento especializado del Derecho público o Derecho privado. 


\subsubsection{División del derecho, naturaleza jurídica del derecho de familia}

En la actualidad, sin embargo, la doctrina comparada es unánime al negar la posibilidad de que pueda configurarse una competencia exclusiva del Juez de Familia en asuntos de faltas o delitos productos de violencia familiar. El derecho, a través de la doctrina, ha desarrollado cuando menos tres importantes conceptos distintos en lo que se refiere a la distinción entre derecho público y derecho privado.

La doctrina tradicional a través de la summa divisio iuris de Ulpiano planteo la distinción del Derecho Público del Derecho Privado. Es con esta distinción, que se establece la existencia de dos grandes reductos de lo jurídico, y en torno a la cual se ha sistematizado todos los ordenamientos jurídicos hasta nuestros días. Se ve fácilmente, que la directriz está orientada a regular relaciones entre individuoEstado, como Derecho Público, y relación individuoindividuo como Derecho privado.

La segunda posición doctrinaria, sostenida por Antoni citado por Alex Placido en su libro (Placido, 2001, pág. 21) donde se afirma una división tripartita del Derecho: Derecho Público, Derecho Privado y Derecho Social. Explica que el «Derecho Social» el sujeto, es la sociedad, representada por los distintos entes colectivos con los cuales opera; por la naturaleza de la relación se está ante una reciprocidad, y cuando se ejerce un derecho se cumple con un deber y es reciproca la exigibilidad. Dentro de ese esquema, coloca al derecho de familia como rama del derecho social, junto al derecho de trabajo y el de seguridad social. De su posición extrae como consecuencia la inaplicabilidad al Derecho de Familia de los principios del Derecho Civil.

Una tercera posición doctrinaria, que si bien no tiene como fuente a un autor en concreto, examinando las anteriores directrices, exponen, que las relaciones de los sujetos en que ellos se encuentran mediante esta gran división del derecho (referido a Ulpiano) ya fue superada, en razón, en que las relaciones humanas no están normadas por principios fijos, universales y obligatorios. Enfatiza que existe una cuarta divisiones del derecho, este, es el caso por ejemplo del Derecho Comunitario, encargada de regular las relaciones entre Estados Nación, que se diferencia de las otras directrices anteriormente mencionadas.

Como refiere Enrique Varsi Rospigliosi (Varsi Rospigliosi, 2012, pág. 101), hay un gran debate sobre la naturaleza jurídica del Derecho de familia. ¿Será un Derecho Público, Privado, mixto o social? ¿Hay un predominio del Estado o de los individuos? (...). En este sentido, el Derecho de familia es una suigeneris que tiene características que la distinguen de toda las ramas del Derecho, a pesar que se la puede regular de manera similar a estas.

Por su parte Clemente De Diego; (Diego, 1959, pág. 434) no hace más que resaltar el carácter sui generis del derecho de familia, refiere que, la familia es otra de las instituciones que originariamente no pertenece al Derecho; este no hace más que regularla. La familia no fue creada por el Derecho ni pertenece originariamente a él. Esta concepción es también asumida por distintos autores como, María Berenice Díaz (Diaz, 2002, pág. 24); Francisco Javier Sánchez Calero (Sanchez Calero, 2004, pág. 31).

En ese entender, si reconocemos al Derecho de Familia, como rama autónoma, con una función básica y esencial «regular las relaciones familiares», esta será, necesariamente la competencia de un Juez especializado, postulando los caracteres peculiares de la competencia del Juez de Familia como único, para resolver supuestos de hecho que se dan en el entorno familiar, aun cuando constituyan delitos 0 faltas como veremos más adelante.

\subsubsection{La unidad de la teoría del proceso}

El otro tema, esto es, relativo a la Teoría General del Proceso, tendrá, en cambio, una importancia más modesta a los fines de la delimitación de la competencia del Juez de familia. Debemos insistir en la unidad del Derecho procesal, es útil insistir sobre su importancia práctica, además de la teórica. Se puede decir que de preocuparnos en distinguir los procesos judiciales, nos abstenemos de investigar la inversión negativa de los recursos logísticos del Estado. Como puede fundarse una distinción entre dos fenómenos que resuelven un mismo hecho, basta recordar su parte histórica, el tema, nos remonta a su pretérito, el «proceso» como rama del Derecho es de reciente data, si se pretende realizar 
una comparación con el resto de las ramas del Derecho, antes no se enseñaba Teoría del Proceso en las Facultades de Derecho.

En fin, se decía que el «proceso», era una «cuestión de prácticos» por ello se le denominaba «Practica Forense», merece un examen atento al libro de Eduardo J. Couture (Couture, 1981, pág. XV) quien afirma: a comienzos del presente siglo e inclusive avanzado este, las facultades de derecho de las universidades latinoamericanas formaban especialistas en las distintas áreas que conforman las ciencias jurídicas. Así, había civilistas, comercialistas, etc., sin embargo, lo que no se formaba era especialistas en proceso, es decir, procesalistas.

Simplemente estamos diciendo que, "La Teoría General del Proceso» es una sola (civil o penal), a la palabra "proceso», suele agregarse términos como «Derecho» para establecer cierta autonomía al resto de las ramas del derecho. En suma, el «Derecho Procesal» es una sola disciplina autónoma, que sirve a los demás mecanismos procesales especializados, tal es así, que, en los países bajos de Noruega, Suecia y Dinamarca no hay Código Procesal Civil, ni tampoco Código Procesal Penal, sólo hay un Código Procesal, que el juez aplica adecuando al caso concreto, aun cuando los serios problemas de orden procedimental que aparecen en la prosecución de los delitos relacionados a la violencia familiar han llevado a algunos autores a proponer la creación de juzgados especializados en los delitos de violencia domestica (Reyna Alfaro, 2011, págs. 352-353).

\subsubsection{La autonomía del derecho de familia}

Como se advierte, tradicionalmente se ha considerado que, el Derecho de Familia, es una subrama del Derecho civil, sin embargo, puesto que este último se estructura sobre la base de la persona individual y que habitualmente se ha estimado que las relaciones de familia no pueden quedar regidas sólo por criterios de interés individual y la autonomía de la voluntad, en la actualidad gran parte de la doctrina considera que es una rama autónoma del Derecho, con principios propios, por ende, requiere su propio código.
La palabra códex o códice nace para denominar a una nueva forma de presentar los trabajos escritos. A partir de este origen, hoy en día se conoce como código a la compilación de leyes, efectuadas de manera sistemática, que procura reunir en una sola obra todo el saber o conocimiento relativo a una rama del derecho como refiere Luis Moisset de Espanes (Espanes, 1994, pág. 193), "un código, es una colección sistemática de leyes que regulan conductas humanas en un determinado Estado».

Según Enrique Varsi Rospigliosi, (Varsi Rospigliosi, 2012, pág. 144) desde los inicios de la codificación, las relaciones de familia siempre han estado presentes en los códigos civiles (antecedente del Code francés de 1804). Es recién en el primer decenio de los novecientos que la URSS regulo el Derecho de familia de manera independiente sumándose Algeria, Bolivia, Bulgaria, California, Cataluña, El Salvador, Estonia, Filipinas, Francia, Hidalgo, Honduras, Hungría, Inglaterra, Lesotho (Acta de Matrimonio) , New York (actas), Ontario, Polonia, Panama, República Popular China Rumania, Rusia, Texas, Yugoslavia, con sus respectivos códigos de familia.

El problema que aquí queremos examinar, no quiere decir que su solución depende de una Codificación en materia Familiar que también ayudaría, por el contrario, la solución depende de la aplicabilidad de la ley a determinadas relaciones distintas, a fin de considerarse una verdadera y propia legislación que deslegitima al derecho penal y civil, consiste en determinar, si puede considerarse a la «violencia familiar» con normatividad distinta al derecho civil y derecho penal. Es necesario observar, por tanto, si el ordenamiento jurídico puede imponer a un sujeto reglas de conducta en el interés predominante de otros.

Sin embargo, cabe diferenciar al Derecho de familia del Derecho civil, desde el punto de vista de su protección, si bien es cierto, en el derecho civil se distingue los derechos patrimoniales y extrapatrimoniales, concibiéndose al Derecho de familia dentro de este último, las sanciones que la norma impone al Derecho de familia, es de otra índole, respecto de las patrimoniales $y$ extrapatrimoniales, como son, perdida de la patria potestad, divorcio, etc. De otro lado, es sabido, que 
la legislación considera al «Derecho de familia», más merecedores de protección, y la tutela eficazmente, sustrayéndolo a la iniciativa de los particulares como refiere Michele Giorgianni (Giorgianni, 1958, pág. 40) «(...). Pero debe notarse que, mientras respecto a los bienes patrimoniales, el ordenamiento deja de ordinario en libertad a los individuos para que regulen sus relaciones (mediante contrato, o genéricamente el negocio jurídico), respecto a los bienes de otra clase, éste recoge algunos que considera más merecedores de protección y los tutela eficazmente sustrayéndolos a la iniciativa de los particulares (como en el derecho de familia), mientras respecto de los demás bienes no patrimoniales éste asume una postura de absoluta indiferencia. (...)».

Por lo expuesto anteriormente, el derecho de familia, reviste caracteres peculiares que lo diferencian de las otras ramas del derecho civil. La influencia de la ideas morales y religiosas, en la adopción de las soluciones legislativas, referentes a los problemas que se presenta, y la necesidad de que sus normas guarden correlación con la realidad social, lo que hace, que su regulación, sea un problema de política legislativa.

Así mismo, cabe recordar, la mayor restricción de la autonomía privada en el «Derecho de familia» que en otras ramas del derecho civil, pues casi todas sus normas son imperativas. Al efecto, las leyes imperativas establecen soluciones de aplicación inexorable, o bien prevalecen sobre cualquier acuerdo diverso de los particulares sometidos a ellos.

Recordemos que, al interior de una familia, la desavenencia conyugal, dependiendo de su magnitud, provoca desde una simple rencilla, hasta el distanciamiento definitivo entre los cónyuges, que por lo general, va acompañada de actos vejatorios de distinto grado, afectando, en última instancia, la integridad física o psíquica de uno de ellos, de ambos y/o de los hijos.

La complejidad de las emociones experimentadas, por los integrantes de una familia en conflicto, merece un tratamiento especializado. La realidad demuestra, que la sola solución legal del conflicto familiar no es suficiente, por no cubrirse debidamente las consideraciones de carácter extralegal. Es por esto, que el conflicto familiar sigue latente, en cualquier momento, se vuelve a desbordar. Se debe procurar, superar las dificultades emocionales que se presentan, en los integrantes de la familia, a fin de que, el conflicto sea mejor asimilado y se aminoren sus efectos.

\subsection{Análisis de la competencia en procesos de Violencia Familiar para medir la inversión negativa de los recursos logísticos del Estado}

Uno de los objetos de la legislación, es determinar los derechos y las obligaciones de todos y cada uno de los particulares y el proceso que le corresponde según su naturaleza civil o penal. Pero esa determinación seria incompleta e ilusorio si no se formula «la utilidad práctica de la norma». En nuestro caso el proceso instaurado en vías paralelas.

Los procesos judiciales no son vanas formulas, se requiere estudiar su utilidad en un caso en concreto, en el presente caso; "la competencia del Juez en Proceso de Violencia Familiar y su paralelo Faltas contra la persona o Delito». La inconveniencia de una doble vía, su necesidad en la práctica judicial se deduce de un estudio por encima de su objeto civil y penal.

Es justamente esta distinción, el que determinara la importancia de todo intento de reforma legislativa el procurar el estudio de la práctica o realidad judicial. El Derecho no se reduce, a conocer la norma jurídica y la aplicación de esta al caso en concreto. Sobre el particular, se requiere un estudio sobre la innecesaria carga procesal, justamente por esa vía paralela, por ello es indispensable conocer en su más minuciosos detalle para evitar inversiones negativas en los recursos logísticos del Estado.

La aplicación práctica de la norma jurídica procesal, es una de las razones de la existencia de la figura de Juez especializado, la que demanda más tiempo y contracción, a causa de la multiplicada variedad de las instituciones y diligencias judiciales; darle al Juez, la función de la aplicación práctica de una norma jurídica, sin utilidad, es perder el horizonte, supone un gasto innecesario de recursos logísticos del Estado.

Casos hay, en que la instauración del proceso judicial no justifica suficientemente, la existencia de dos 
procesos de los que se tiene los mismos motivos, sujetos y hechos. La experiencia, es el elemento primordial para darse cuenta, para censurar, la inconveniencia de una doble vía.

Dentro de esa directriz jurídica procesal vigente en tema de "Violencia Familiar», la diferencia entre Derecho Penal y Derecho Civil, innecesariamente multiplica la variedad de las diligencias judiciales del «Derecho de familia», destinadas justamente a resolver un solo conflicto de intereses, ya sea delito o falta, que debe ser tratada como un problema social, en el entorno familiar.

Sucede, en efecto, que el tratamiento de la violencia familiar en el ámbito civil se inicia con la denuncia ante la Policía Nacional 0 al Representante del Ministerio Público (Fiscalías de Familia y/o fiscalías mixtas donde no existen fiscalías especializadas), que obliga realizar las diligencias preliminares a fin de investigar los actos que constituyen violencia familiar.

Una vez acreditado el vínculo familiar y los medio probatorios que acrediten los hechos constitutivos de violencia familiar, el Fiscal de Familia, formaliza la demanda ante el Juez de Familia, así mismo, en atención a los días de asistencia o descanso prescritos a la víctima, remitirá copias certificadas de los actuados al Juez de Paz letrado o Juez Penal para que tome conocimiento conforme a sus atribuciones. (Sucede a veces que la Policía Nacional también pone en conocimiento a los Juzgados de paz Letrado o en su caso al Juzgado Penal teniendo en cuenta si el hecho de violencia familiar constituye delito 0 falta).

La competencia del órgano jurisdiccional puede resumirse en lo siguiente:

El artículo $96^{\circ}-\mathrm{A}$ de la Ley Orgánica del Ministerio Público en su numeral 4) establece las atribuciones de los Fiscales de Familia en «Intervenir en todos los asuntos que establece el Código de los Niños y Adolescentes y la Ley que establece la política del Estado y la sociedad frente a la violencia familiar.»

En ese sentido el capítulo segundo del TUO de la ley frente a la violencia familiar regula la intervención del Ministerio Público, señalando en el artículo $9^{\circ}$ «El Fiscal Provincial de Familia que corresponde dará tramite a las peticiones que se formulen verbalmente o por escrito en forma directa por la víctima de violencia, sus familiares, (...)».

Conforme señala el artículo $10^{\circ}$ de la referida norma el Fiscal de Familia está en la obligación de imponer las medidas de protección inmediatas en resguardo de la víctima las que deberán dictarse en el plazo de 48 horas; y el artículo $16^{\circ}$ refiere también que culminada la investigación el Fiscal además de haber dictado las medidas de protección inmediatas interpondrá demanda ante el Juez de Familia solicitando además la confirmación de las medidas de protección impuestas.

En cuanto a la intervención del Juez de Familia el propio Texto Único Ordenado en análisis señala en su artículo $18^{\circ}$ que corresponde el conocimiento de los procesos de violencia familiar al Juzgado especializado de Familia del lugar donde domicilia la víctima o del lugar de la agresión, indistintamente. El proceso se tramitará de conformidad con el proceso único regulado en el Código de los Niños y Adolescentes.

Como se advierte, Sucede en efecto, la existencia de casos de violencia familiar, que simultáneamente constituyen faltas contra la persona 0 incluso delito, es por ello que el sub capitulo segundo del capítulo tercero de TUO analizando en la presente regula la intervención del Juez Especializado en lo Penal y del Juez de Paz Letrado, señalando que éstos también tiene facultades para imponer medidas de protección que el caso lo requiere, pero ello no obstaculiza a que se tramiten también estos casos ante el Juzgado de Familia de la Jurisdicción como Violencia familiar.

En efecto, el Fiscal Penal, en caso de delito, asume la tarea acusadora y es el Juez o tribunal quien impondrá una pena en caso de lesiones producto de violencia familiar, pero, nada impedirá que el Fiscal de Familia, de conformidad a sus atribuciones, pueda interponer su demanda por Violencia Familiar, ante el Juez de Familia.

Posición diversa del ofendido en violencia familiar, sucede en caso de que el hecho que constituye «violencia familiar» configure a la vez «faltas contra la persona», en este caso, se requiere que el trámite 
se por acción privada, directamente por el ofendido ante el Juez de Paz Letrado, pero, igualmente, se remite los actuados.

Un ejemplo, de aminorar la carga procesal, tenemos en la Directiva No 005-2009-MP-FN.

La Directiva del Ministerio Público establece que la actuación tanto del Fiscal Penal y el de Familia cuando existan hechos que a la vez constituyan delito y violencia familiar, señalando en el artículo $28^{\circ}$ Frente a la comisión de un hecho punible que al mismo tiempo constituyan violencia familiar, el principio de unidad de actuación del Ministerio Público, exige una estrategia de trabajo coordinada entre el Fiscal de Familia y el Fiscal penal. Para ese efecto el Fiscal de Familia, se comunicara con el Fiscal Penal para ponerse de acuerdo sobre la determinación de las medidas de protección inmediatas y el Fiscal que las solicitara el acuerdo o la falta de éste, deberá constar en acta, que se anexara a las respectivas investigaciones fiscales. En caso que no haber acuerdo, corresponde al Fiscal Penal solicitar las medidas de protección, las que comunicara al Fiscal de Familia. En este caso, será obligatoria la derivación de la presunta víctima a la Unidad de Asistencia de Víctimas y Testigos.

En consecuencia, solo tomando esta última postura de la Directiva señalada anteriormente, la satisfacción del interés de la víctima de la violencia familiar se verá satisfecha, al igual que la carga procesal en los juzgados especializados y fiscalías especializadas se verán disminuidas.

\subsection{Apuntes para una dogmática jurídica de la inconveniencia de la triple vía en supuestos de hecho que configuran violencia familiar}

No existe país donde el tema judicial, que está destinado asegurar la primacía de la ley cuando se enfrenta a un «caso justiciable», no haya producido insatisfacciones en su población. Esta situación tiene una explicación histórica definida. El congreso emite leyes; el Presidente de la República emite decretos y visa resoluciones; el Poder Judicial emite resoluciones de administración de justicia. Cada uno de estos poderes que devienen de montesquiu se encuentran estrechamente vinculados, pero cada uno con funciones distintas e independientes, producto a partir del siglo XVI de nuestra humanidad.
La efectividad de la división de poderes, dependerá del ejercicio responsable de los miembros que la componen. La emisión de normatividad, requiere hoy en día, de sacudirse de esa vieja concepción, de que las normas se sobreponen a la realidad social como «imposición», los conflictos, ahora, requieren ser estudiados, para luego emitir la normatividad, como solucionadora al conflicto que se presenta, y que la razón descubre, mediante el examen de convivencia, aceptada por la población.

En ese entender, el concepto de familia sufrió una serie de modificaciones en los últimos tiempos, las razones históricas, nos revela los acontecimientos que influyeron en el ánimo del legislador para expedirla. Hoy su desarrollo resultas ser claro, el clásico modelo de padre, madre, esposos, hijos, tíos primos etc., se le han sumado ahora: Los convivientes, los hijos ensamblados (Caso Shols Pérez, (STC Exp. No 09332-2006-PA/TC-Lima). El $T C$ reconoce a la familia ensamblada o reconstruida como forma de organización familiar), los ex cónyuges, los ex convivientes, los que habitan en un mismo hogar. Así que cualquier acto (activa o omisiva) de violencia física o verbal (psicológica) o inclusive maltrato sin lesión o la amenaza o coacción o violencia sexual que se produzca entre estas personas se considera violencia familiar.

Según Greyse León citado por Manuel F. Chávez Asencio (Chávez Asencio, 2002), "cada quince segundos una mujer es golpeada por el marido o por la pareja masculina. A nivel mundial, según las estadísticas, el $75 \%$ de las víctimas del maltrato familiar son mujeres. Las mujeres y los menores son los blancos perfectos en el hogar para ejercer un tipo certero de violencia física y sexual, presiones y control psicológico, por los sectores más vulnerables de la población». Por ello, se requiere políticas de Estado para su protección.

El Estado peruano, con la Constitución Política de 1993, según Violeta Bermúdez Valdivia (Bermúdez Valdivia, 2002, págs. 73-74), no consagra expresamente el derecho a gozar de una vida libre de violencia dentro del espacio familiar, el reconocimiento establecido en él es genérica, se materializa en el artículo $2^{\circ} 1$ ) de la Constitución Política establece que, «toda persona tiene derecho a la vida, a su identidad, a su integridad moral, 
psíquica y física y a su libre desarrollo y bienestar (...)». Del mismo modo, el numeral 24-h) del mismo artículo señala que «nadie debe ser víctima de violencia moral, psíquica o física, ni sometido a tortura o a tratos inhumanos o humillantes». Igualmente, el artículo $2^{\circ}$ del texto fundamental reconoce el derecho de las personas a la igualdad, prohibiéndose todo acto de discriminación por razón de origen, raza, sexo, idioma, religión, opinión, condición económica o de cualquier otra índole.

Así mismo, el legislativo, se vio obligado a promulgar una ley especial contra la Violencia Familiar de conformidad a los convenios internacionales que nos vinculan sobre erradicación de estas formas de violencia. Dichos instrumentos son: Pacto Internacional de los Derechos Civiles y Políticos o la Convención Americana sobre Derechos Humanos, la Convención para Prevenir, Sancionar y Erradicar la Violencia contra la Mujer y la Convención sobre la Eliminación de todas las Formas de Discriminación contra la Mujer.

Como consecuencia de las obligaciones internacionales antes citadas, el Estado peruano promulgó la Ley $N^{\circ} 26260$, Ley de Protección Frente a la Violencia Familiar (Dicha norma fue modificada en varias oportunidades, por lo que en junio de 1997 se promulgó el DS 006-97 JUS, Texto Único Ordenado de la Ley $26260^{\circ}$, Ley de Protección Frente a la Violencia Familiar), la misma que otorga a la víctima de violencia familiar una protección de carácter específicamente tutelar. (Terminología derivada del artículo $53^{\circ}$ de la Ley Orgánica del Poder Judicial).

La definición de «violencia familiar», viene del artículo $2^{\circ}$ del TUO (Texto Único Ordenado aprobado mediante D.S N $\mathrm{N}^{0}$ 006-97-JUS y su reglamento aprobado por D.S N ${ }^{0}$ 002-98-JUS) de la Ley de Violencia Familiar 26260 modificado por ley 27306 y 29282 establece la definición de la violencia familiar señalado "A los efectos de la presente Ley, se entenderá por violencia familiar, cualquier acción $u$ omisión que cause daño físico o psicológico, maltrato sin lesión, inclusive la amenaza o coacción graves y/ o reiteradas, asi como la violencia sexual, que se produzcan entre:
a) Cónyuges
b) Ex cónyuges

c) Convivientes

d) Ex convivientes

e) Ascendientes

f) Descendientes

g) Parientes colaterales hasta el cuarto grado de consanguinidad y segundo de afinidad.

h) Quienes habitan en el mismo hogar, siempre que no medien relaciones contractuales o laborales. i) Quienes hayan procreado hijos en común, independientemente que convivan o no, al momento de producirse la violencia

j) Uno de los convivientes y los parientes del otro hasta el cuarto grado de consanguinidad y segundo de afinidad, en las uniones de hecho.

Esta definición, así planteada, pareciera implicar necesariamente, el pronunciamiento del órgano jurisdiccional en un caso justiciable, distinguiendo su naturaleza: civil o penal. Esta posición representara una posibilidad de ordenar y ver el Derecho. Es valida en cuanto un supuesto de hecho, que el ordenamiento tipifique como «Violencia Familiar», nada impedirá que de la misma, derive a la vía penal, como un tema de delito o falta.

Nada más alejado de la realidad, sin embargo, desde que los fundamentos anteriormente expuestos de la ley de "Violencia Familiar» debieran reconocer competencia exclusiva al Juez de familia aun cuando los hechos constituyan delito o falta, nada tiene que ver la jurisdicción penal por cuanto su especialidad la deslegitima para conocer asunto de familia en aras reconocer el principio de la economía procesal y el no vis in ídem. Aun cuando no exista uniformidad en la legislación comparada en torno al segundo, la necesidad de unificar el proceso penal, conjuntamente con el proceso civil, deviene en la Economía Procesal.

En tal sentido, un supuesto de hecho, que tipifique "violencia familiar», y que a la vez derive consecuencias penales, precisamente, porque el Derecho brinda protección a los intereses de las víctimas, requiere de la intervención única y exclusiva del Juez de Familia, por la naturaleza de la controversia y por un tema de economía procesal.

De otro lado, el Ordenamiento Procesal en los Juzgados de Familia, resuelve casos de «Acto Infractor a La ley Penal» aplicando el Derecho Penal 
al caso en concreto. Simplemente el argumento de falta de especialidad en Derecho Penal por parte del Juez de Familia queda desvirtuada.

Como refiere Radhika Coomaraswamy (Coomaraswamy, 2000, pág. 11), cuando refiere a la violencia familiar, «toda política que sea incapaz de reconocer la naturaleza particular de estos delitos 0 no vaya acompañada de tentativas de brindar apoyo a las víctimas y asistencia al agresor estará inevitablemente destinada al fracaso».

En ello descansa la importancia de realizar un estudio, cuyo objetivo principal sea analizar las deficiencias e irregularidades en el funcionamiento del sistema de Justicia Penal, Justicia de Paz Letrado y Justicia de Juez de Familia, respecto del procedimiento de faltas o delitos por violencia familiar. Sobre todo, si tenemos en cuenta que en el caso peruano el mayor número de denuncias por violencia familiar con relevancia penal se concentra en aquellas infracciones leves (faltas) que contempla el artículo $441^{\circ}$ del Código Penal.

De aquí es que la legislación positiva debe tomar en cuenta la especialidad del juez, la que encuentra fundamento en la misma vida de relación de familia a menudo en conflicto, innecesariamente bifurcada en la vía paralela (penal y civil), toda vez que, los intereses siempre, sea como quiera, son similares, son los mismos hechos, por lo que no puede prescindirse para que se proceda según la naturaleza familiar de la petición. Este es el método de proponer, tramitar y resolver las diferentes pretensiones de los particulares sobre asuntos de familia, porque sin la especialización, la triple competencia asumida en el caso peruano sería un conjunto de disposiciones injustas e incoherentes, que pondrían la justicia en manos de la casualidad, deducciones meramente técnicas, que conducirían inevitablemente a error.

En esta orientación, la inconveniencia de la llamada triple competencia de la Ley $N^{\circ} 26260$ se resume en las razones que motivan la competencia exclusiva del juez de familia en asuntos de violencia familiar.

\section{RESULTADOS.}

De las 1232 demandas por Violencia Familiar del Primer Juzgado de Familia de la ciudad de Puno (1JFP), 96 procesos por Faltas contra la persona se judicializaron en los Juzgados de Paz letrado por los mismos hechos $\left(1^{\circ}, 2^{\circ}, 3^{\circ}\right.$ y $4^{\circ}$ Juzgado de Paz Letrado de la ciudad de Puno).

De las 1238 demandas por Violencia Familiar del Segundo Juzgado de Familia de la ciudad de Puno (2JFP), 79 procesos por Faltas contra la persona se judicializaron en los Juzgados de Paz letrado por los mismos hechos $\left(1^{\circ}, 2^{\circ}, 3^{\circ}\right.$ y $4^{\circ}$ Juzgado de Paz Letrado de la ciudad de Puno).

El número de expedientes se detallan en los cuadros 3 :

\begin{tabular}{|c|c|c|c|c|}
\hline $\begin{array}{l}\text { Primer Juzgado de } \\
\text { Familia (1232 } \\
\text { expedientes) }\end{array}$ & $\begin{array}{l}\text { Primer Juzgado } \\
\text { de Paz Letrado }\end{array}$ & $\begin{array}{l}\text { Segundo Juzgado de } \\
\text { Paz Letrado }\end{array}$ & $\begin{array}{l}\text { Tercer Juzgado de } \\
\text { Paz Letrado }\end{array}$ & $\begin{array}{l}\text { Cuarto Juzgado } \\
\text { de Paz Letrado }\end{array}$ \\
\hline $\begin{array}{c}\text { 96 expedientes } \\
\begin{array}{l}\text { Segundo Juzgado de } \\
\text { Familia (1238 } \\
\text { expedientes) }\end{array}\end{array}$ & $\begin{array}{l}\text { Primer Juzgado } \\
\text { de Paz Letrado }\end{array}$ & $\begin{array}{l}\text { Segundo Juzgado de } \\
\text { Paz Letrado }\end{array}$ & $\begin{array}{l}\text { Tercer Juzgado de } \\
\text { Paz Letrado }\end{array}$ & $\begin{array}{l}\text { Cuarto Juzgado } \\
\text { de Paz Letrado }\end{array}$ \\
\hline 79 expedientes & 10 & 23 & 10 & 36 \\
\hline Total:175 expedientes & 21 & 38 & 31 & 84 \\
\hline
\end{tabular}

\section{CONCLUSIONES}

La emisión de normatividad sobre Derecho de Familia, requiere hoy en día, de superar esa vieja concepción, de que las normas se sobreponen a la realidad social como «imposición en vías paralelas», los conflictos familiares ahora, requieren ser estudiados, para luego emitir la normatividad, como solucionadora única al conflicto que se presenta, y que la razón descubre, mediante el principio economía procesal.

Un supuesto de hecho, que tipifique «violencia familiar», y que a la vez derive consecuencias penales, requiere de la intervención única y exclusiva del Juez de Familia, por la naturaleza de la 
controversia y por un tema de economía procesal. El Derecho de Familia, como rama autónoma cumple una función básica y esencial, «regular las relaciones familiares».

«La utilidad práctica de la «norma» de Derecho de familia, evitara gastos innecesarios de los recursos logísticos del Estado. La complejidad del Derecho de familia, merece un tratamiento especializado. La realidad demuestra, que la sola solución legal del conflicto familiar no es suficiente, por no cubrirse debidamente las consideraciones de carácter extralegal. Es por esto, que el conflicto familiar sigue latente, en cualquier momento, se vuelve a desbordar.

\section{BIBLIOGRAFÍA}

Bermúdez Valdivia, V. (2002). Los Derechos de las Mujeres: Aportes al debate Constitucional. En:Mujer y Reforma Constitucional: Aporte para el debate. Lima: Mujer

y Reforma Constitucional.

Betti, E. (1969). Teoría General de las Obligaciones. Madrid: Revista de Derecho Privado.

Chávez Asencio, M. (2002). Conflictos familiares. Mecanismos alternativos de solución de conflictos. Colombia: Universidad Externado de Colombia.

Coomaraswamy, R. (2000). La Lucha contra la Violencia: Las Obligaciones del Estado. En: La Violencia Doméstica contra
Mujeres y Niñas UNICEF. Italia: UNICEF.

Couture, E. J. (1981). Fundamento del Derecho Procesal Civil. Buenos Aires: Depalma.

Diaz, M. (2002). Manual de Direito Das familias (cuarta edición ed.). Sao Paolo: Revista dos tribunais Atlas.

Diego, C. D. (1959). Instituciones de Derecho Civil español. Madrid: Artes Gráficas Julio San Martin.

Espanes, L. M. (1994). Codificación Civil y Derecho Comparado. Buenos Aires: Zabalia.

Ferrajoli, L. (1989). Derecho y Razón: Teoria del Garantismo Penal. Italia.

Giorgianni, M. (1958). La obligación. La parte Generalde las Obligaciones. (E. V. Tuells, Trad.)

Barcelona: Bosch.

Montero Aroca, J. (1979). Introducción al Derecho Procesal. Madrid: Tecnos.

Placido, A. (2001). Manual de Derecho de Familia. Lima: Gaceta Jurídica.

Reyna Alfaro, L. (2011). Delitos Contra la Familia y de Violencia Domestica (2da edición ed.). Lima: Jurista Editores E.I.R.L.

Sanchez Calero, F. (2004). Curso de Derecho Civil IV Derecho de familias y sucesiones (3ra edición ed.). Valencia: Tirant Blanch.

Varsi Rospigliosi, E. (2012). Tratado de Derecho de Familia (Vol. Tomo I). Lima: Gaceta Jurídica. 